\title{
Ecologia da paisagem e qualidade ambiental de remanescentes florestais na sub-bacia hidrográfica do Rio Atibaia dentro do município de Campinas-SP
}

\author{
Landscape ecology and environmental quality of forest remnants in Atibaia \\ River sub-basin covering the municipality of Campinas, SP
}

\author{
Alessandra Leite da Silva ${ }^{\mathrm{I}}$, Regina Márcia Longo ${ }^{\mathrm{II}}$
}

\begin{abstract}
Resumo
A fragmentação florestal é um dos fatores que interferem na sustentabilidade dos recursos naturais, biodiversidade e qualidade de vida. Diante disso, são essenciais estudos que avaliem quanti e qualitativamente as propriedades ambientais de determinado ecossistema e/ou paisagem. Para tanto, a análise da ecologia da paisagem atua de forma eficaz. Diante disso o presente estudo buscou avaliar, a partir de métricas de paisagem, a qualidade dos remanescentes florestais presentes na parte da sub-bacia hidrográfica do rio Atibaia que cobre o município de Campinas/SP. Para tanto, utilizaram-se as métricas: Tamanho; Índice de Área Central; Índice de Circularidade; Distância do Vizinho mais Próximo; Proximidade à Curso d'Água; Produção de Água; Grau de Uso e Ocupação do Solo no Entorno e Grau de Erodibilidade do Solo. Estas foram analisadas individualmente e através do Índice de Qualidade Ambiental $\left(I_{Q_{r e m}}\right)$. Verificou-se o alto grau de fragmentação florestal, dado o elevado número de remanescentes, especialmente pequenos e com baixa representativa de área central, porém localizados próximos uns aos outros. Além disso, por tratar-se de sub-bacia produtora de água para abastecimento, ressalta-se a necessidade de estratégias específicas de conservação desses remanescentes a fim de garantir a produção de água em termos quantitativos e qualitativos.
\end{abstract}

Palavras-chaves: Métricas de paisagem; Fragmentação florestal; Infraestrutura verde

\begin{abstract}
Forest fragmentation is one of the factors which interfere in the sustainability of natural resources, biodiversity and life quality. In view of this, studies that assess the quantitative and qualitative environmental properties of a given ecosystem and/or landscape are essential. Therefore, the analysis of landscape ecology acts effectively. Thus, the present study aimed to evaluate, based on landscape metrics, the quality of the forest remnants presents in the Atibaia river sub-basin covering the municipality of Campinas / SP. For that, the following metrics were used: Size; Central Area Index; Circularity Index; Distance from the Nearest Neighbor; Proximity to the Watercourse; Water Production; Degree of Land Use and Occupation in the Surroundings and Degree of Soil Erodibility. These were analyzed individually and through the Environmental Quality Index $\left(I Q_{r e m}\right)$. There was a high degree of forest fragmentation, given by the high number of remnants, especially small and with a low representative central area, however, located close to each other. In addition, as this watershed is a water-producing for supply, the need for specific conservation strategies for these remnants is emphasized, in order to guarantee water production in quantitative and qualitative terms.
\end{abstract}

Keywords: Landscape metrics; Forest fragmentation; Green infrastructure

\footnotetext{
Engenheira Ambiental, Ma., Doutoranda em Ciências Ambientais, Universidade Estadual Paulista "Júlio de Mesquita", Campus Sorocaba, Av. Três de Março, 511, Alto da Boa Vista, CEP 18087-180, Sorocaba (SP), Brasil. alessandra.leite@unesp.br (ORCID: 0000-0001-6534-2122)

Engenheira Agrônoma, Dra., Professora do Centro de Ciências Exatas, Ambientais e de Tecnologia, Pontifícia Universidade Católica de Campinas, Rua Professor Dr. Euryclides de Jesus Zerbini, 1516, Parque Rural Fazenda Santa Cândida, CEP 13087-571, Campinas (SP), Brasil. regina.longo@ puc-campinas.edu.br (ORCID: 0000-0002-2374-4649)
} 


\section{Introdução}

Dentre as mais graves e adversas implicações para a ecologia provenientes da urbanização acelerada e sem o adequado planejamento está o aumento das áreas construídas e a consequente redução das áreas de vegetação natural, áreas úmidas, corpos d'água e terras agricultáveis. O aumento das áreas impermeáveis leva à diminuição da recarga dos aquíferos, promovendo a queda no nível d'água subterrânea e na quantidade disponível, aumentando a demanda de água em nível comercial e doméstico e, consequentemente, colocando graves ameaças à sustentabilidade do processo de urbanização (PATRA et al., 2018).

Outras consequências da urbanização sem o adequado planejamento são: aumento da evapotranspiração; aumento da concentração de gases do efeito estufa e da poluição atmosférica; distúrbios nos ecossistemas naturais e perda de biodiversidade (PATRA et al., 2018; WU et al., 2018). Sendo assim, diante de tantas questões ambientais que têm sido enfrentadas como resultado dos danos sofridos pelos ecossistemas naturais devido o fenômeno da urbanização, atualmente uma das questões-chave para promover um desenvolvimento urbano sustentável é a necessidade de coordenar a relação entre a urbanização e meio ambiente (WU et al., 2018), processo denominado "planejamento".

Para desenvolver um planejamento urbano eficaz é necessário compreender as sinergias que existem entre os fatores ecológicos e os fatores sociais (ANDERSSON et al., 2014; HERSPERGER et al., 2018). Essa compreensão do ambiente urbano integrado ao ambiente natural está consolidando-se cada vez mais e é evidenciada pelos recursos mais comuns disponíveis neste ambiente. Esses recursos podem ser tanto materiais (terra, moradia, infraestruturas, equipamentos, espaços públicos, espaços verdes) quanto imateriais (informação, conhecimento, cultura, segurança); naturais (água, ar, biodiversidade) e artificiais (conhecimento social, cultural ou coletivo); universais (cujo acesso deve ser garantido a todos) e produzidos localmente; abundantes e escassos, e assim por diante (CASTRO-COMA; MARTÍ-COSTA, 2016).

De forma geral, o processo de urbanização está relacionado a complexas mudanças no uso e ocupação do solo, tanto em termos de tipologia quanto de grau de uso e ocupação, promovendo a fragmentação das paisagens. Dessa forma, o parcelamento do solo é um dos motivos pelos quais o processo de fragmentação da paisagem vem causando tanto a redução das áreas de cobertura vegetal quanto à distribuição fragmentada das mesmas e interferindo na sustentabilidade dos recursos naturais, da biodiversidade e, portanto, na qualidade de vida da sociedade (CHAVES; SANTOS, 2009; ANDERSSON et al., 2014;MASSOLI; STATELLA; SANTOS, 2016).

No contexto das cidades, apesar da infraestrutura verde ter capacidade de fornecer uma multiplicidade de serviços, denominados serviços ecossistêmicos, para que isso aconteça de forma eficaz é essencial o monitoramento da vegetação natural, tanto com relação à sua composição, quanto em termos temporais e distribuição espacial (ANDERSSON et al., 2014; LAWLEY et al., 2016). Os serviços ecossistêmicos são benefícios obtidos a partir da natureza que estão relacionados ao bem-estar humano e, integrá-los ao planejamento urbano é uma maneira eficaz de garantir sua provisão e potencializar seus benefícios em longo prazo. Dessa forma, os investimentos na infraestrutura verde urbana e nos serviços ecossistêmicos providos por esta é, não apenas ecológica e socialmente desejável como também economicamente viável. Quando tais serviços ecossistêmicos passam a ser reconhecidos e quantificados, obtém-se o reconhecimento de uma enorme gama de beneficiários (ANDERSSON et al., 2014).

Dessa forma, para alcançar sua conservação e apoiar uma tomada de decisão racional é essencial que se desenvolva estudos que promovam uma avaliação quanti e qualitativa das propriedades ambientais de determinado ecossistema e/ou paisagem, tais como fragilidade, exploração, estado de conservação e necessidade de recuperação. Como a fragmentação da paisagem envolve causas e efeitos tanto físicos como biológicos, a Ecologia da Paisagem analisa a disposição espacial dos elementos na paisagem por meio de métricas, permitindo que a base geográfica possa subsidiar a abordagem ecológica quando se analisa as alterações biológicas 
e as interações ecológicas resultantes das mudanças ocorridas nos elementos da paisagem (SIQUEIRA; CASTRO; FARIA, 2013)

Diante da necessidade de subsidiar a avaliação de serviços ecossistêmicos em remanescentes florestais, estudos têm sido desenvolvidos com o objetivo de avaliar a vulnerabilidade e fragilidade de ecossistemas e paisagens naturais, es pecialmente de fragmentos florestais a partir de métricas da paisagem (ETTO et al., 2013; LONGO et al., 2019;SILVA et al. 2019). Nesse contexto, o presente trabalho teve por objetivo verificar a eficácia da utilização de métricas de paisagem para a avaliação da qualidade dos remanescentes florestais, aplicando métricas selecionadas em remanescentes florestais da Sub-Bacia Hidrográfica do Rio Atibaia, na região pertencente ao município de Campinas/SP.

\section{Material e métodos}

\section{Área de estudo}

A sub-bacia do rio Atibaia é uma das cinco sub-bacias pertencentes à bacia do rio Piracicaba. O rio Piracicaba faz parte do importante conjunto de bacias hidrográficas, denominado Bacias PCJ. Esse recorte espacial possui área de $15.303,67 \mathrm{~km}^{2}$ e ultrapassa os limites estaduais, sendo 92,6\% no Estado de São Paulo e 7,4\% no Estado de Minas Gerais (MG) e está situada entre os meridianos $46^{\circ}$ e $49^{\circ} \mathrm{O}$ e latitudes $22^{\circ}$ e $23,5^{\circ} \mathrm{S}$ (AGÊNCIA DE ÁGUA PCJ, 2019). A subbacia do rio Atibaia contempla uma área de 25.782,70 ha dentro do município de Campinas, o que equivale a aproximadamente $257,83 \mathrm{~km}^{2}$; esta é área selecionada como recorte neste estudo. Essa parte da bacia apresenta uma área florestal remanescente de 3.298,19 ha, distribuída em 1.368 remanescentes das tipologias: Floresta Estacional Semidecidual (FES), Floresta Paludosa, Floresta Mista, FES+Cerrado, selecionados a partir do levantamento da vegetação natural de Campinas fornecidos pela Prefeitura de Campinas (Figura 1).

\section{Figura 1 - Sub-bacia do rio Atibaia em Campinas/SP e vegetação florestal remanescente}

Figure 1 - Atibaia river sub-basin in Campinas/SP and remaining forest vegetation

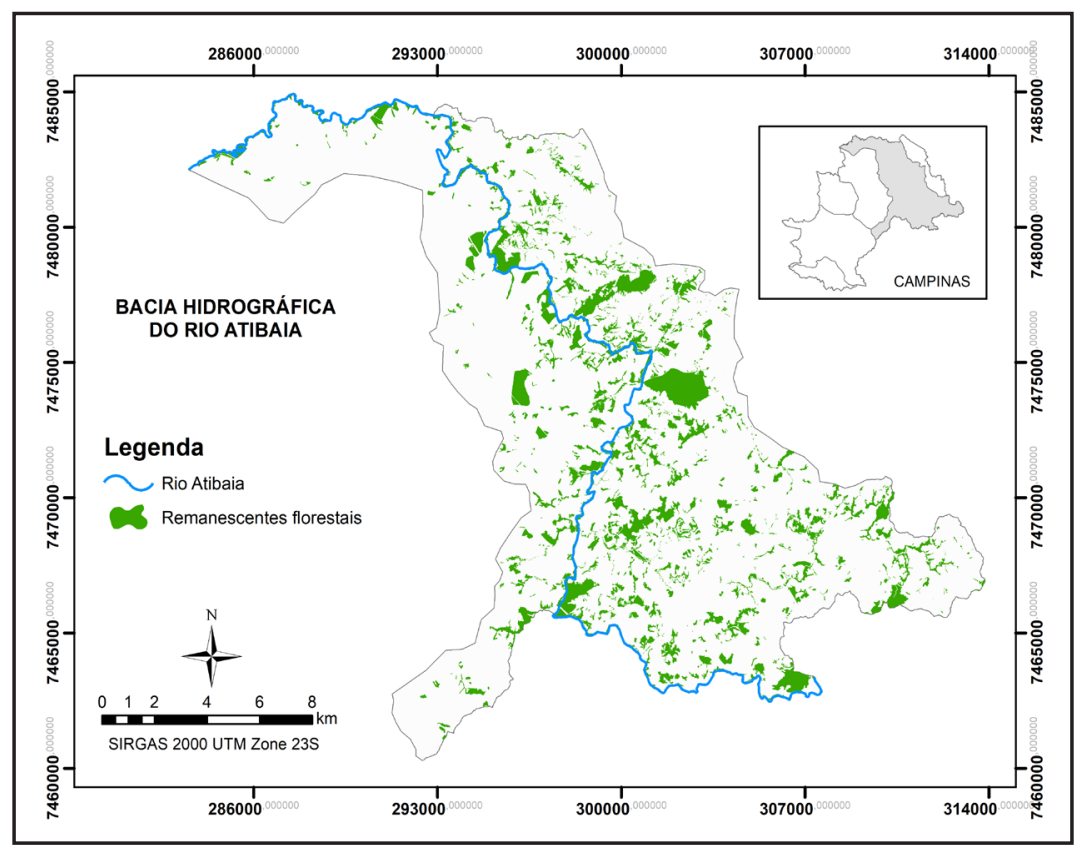

Fonte: Autores (2020) 
O rio Atibaia consiste no principal manancial de abastecimento de Campinas, sendo responsável por atender $93,5 \%$ da demanda. Apesar do significativo percentual de áreas verdes, é perceptível na bacia o contraste entre áreas extremamente urbanizadas e ambientes naturais relativamente preservados (DEMANBORO; LAURENTIS; BETTINE, 2013). Isso torna essa região um importante manancial de abastecimento público tanto de Campinas quanto de municípios vizinhos (DEMANBORO; LAURENTIS; BETTINE, 2013).

$\mathrm{Na}$ região na qual a sub-bacia do rio Atibaia está inserida o clima é do tipo quente, temperado e chuvoso, classificados em três subtipos, segundo a Classificação Climática de Köppen: Cfb, sem estação seca e com verões tépidos, nas porções baixas das bacias PCJ; Cfa, sem estação seca e com verões quentes, nas partes médias das Bacias; e, Cwa, com inverno seco e verões quentes, nas porções serranas das cabeceiras (AGÊNCIA DE ÁGUA PCJ, 2019). Essas são algumas das condições que favorecem as formações florestais tropicais nessa área.

\section{Métricas de paisagem}

As métricas da paisagem utilizadas para análise dos 1.368 remanescentes florestais levantados foram selecionadas da literatura, a partir de estudos com escopo semelhante ao presente estudo e estão apresentadas a seguir (FREITAS, 2012; JESUS et al., 2015; MASSOLI; STATELLA; SANTOS, 2016; FERNANDES; FERNANDES, 2017; LIMA; FRANCISCO; BOHRER, 2017).Todas as análises foram executadas com o software SIGArcGIS.

a) Tamanho do Fragmento (AREA): área total de cada remanescente, pelo qual o tamanho do mesmo pode ser classificado em: muito pequeno $(<0,50 \mathrm{ha})$; pequeno $(0,50-1,00 \mathrm{ha})$; médio (1,00 - 5,00 ha); bom (5,00 - 20,00 ha); e adequado ( $>20,00$ ha) (FREITAS, 2012). Calculou-se ainda o Índice do Maior Fragmento (LPI) que representa o percentual da paisagem ocupada pelo fragmento de maior área (FERNANDES; FERNANDES, 2017).

b) Índice de Área Central (CAI): percentual da área do remanescente que corresponde à área central, sendo esta a área núcleo (core area) do fragmento, desconsiderando a área mais sujeita aos efeitos de borda na faixa de 60m de borda (LIMA; FRANCISCO; BOHRER, 2017).

c) Índice de Circularidade (IC): Grau de semelhança do formato do remanescente com o de uma circunferência, calculado pela Equação (1) e classificado em: formato alongado (IC $<0,65)$, moderadamente alongado $(0,65 \leq \mathrm{IC}<0,85)$ e arredondado (IC $\geq 0,85)$ (ETTO et al. , 2013):

$$
I C=\frac{(2 \sqrt{\pi A})}{L}
$$

d) Distância do Vizinho mais Próximo (ENN): Menor distância (distância euclidiana em metros) de um remanescente florestal ao seu vizinho mais próximo (MASSOLI; STATELLA; SANTOS, 2016; LIMA; FRANCISCO; BOHRER, 2017).

e) Proximidade à Curso d'Água (PROXRIOS) e Produção de Água (AGUA): Enquanto PROXRIOS representa a distância em metros (m) entre o remanescente florestal e o curso d'água mais próximo, onde distâncias iguais a zero indicam que o curso d'água passa pelo interior do remanescente, a métrica AGUA avalia a presença de nascentes dentro da área abrangida pelo fragmento florestal. Para a análise das métricas PROXRIOS e AGUA utilizaram-se os dados geoespaciais de cursos d'água e nascentes provindos do levantamento hidrográfico realizado em 2003 pelo Instituto Geográfico e Cartográfico (IGC) e modificado em 2014 pela Secretaria do Verde, Meio Ambiente e do Desenvolvimento Sustentável (SVDS) da Prefeitura de Campinas em escala de 1:5.000.

f) Grau de Uso e Ocupação do Solo no Entorno (BORDA): A partir de classificação 
do uso e ocupação do solo (SÃO PAULO, 2018) em graus de modificação, segundo Chaves e Santos (2009), foi avaliada quais as classes de maior modificação presentes na área do entorno de cada remanescente. Para tanto, utilizou-se a ferramenta "intersect (3d) the source layer feature".

- Classe 0 - Paisagem não modificada: Paisagens naturais ou quase naturais, com baixíssimo grau de uso e ocupação do solo. Nesta classe estão os remanescentes florestais.

- Classe 1 - Pequena modificação: Vegetação natural com pequena modificação, baixo grau de uso e ocupação, tais como áreas úmidas, campo natural e áreas de reflorestamento.

- Classe 2 - Modificação média: Áreas de transição, com médio grau de uso e ocupação do solo. Incluem espaço verde urbano e pastagens.

- Classe 3 - Alta modificação: Alto grau de uso e ocupação do solo e de modificação da paisagem natural, como as áreas de cultura perene, semiperene ou temporária.

- Classe 4 - Modificação muito alta: Áreas completamente modificadas, com altíssimo uso e ocupação do solo, como áreas edificadas, loteamentos e solo exposto.

g) Grau de Erodibilidade do Solo (EROD): Avaliação do grau de erodibilidade do solo a partir da tipologia de solo predominante em cada remanescente florestal. A associação entre pedologia da sub-bacia do rio Atibaia e grau de erodibilidade foi realizada a partir do Mapa Pedológico Semidetalhado do Município de Campinas (EMBRAPA, 2008) e a classificação adaptada de Silva e Oliveira (2015) em grau de erodibilidade, conforme apresentada a seguir e na Figura 2.

- Muito Fraco: Gleissolos Háplicos (GX)

- Fraco/ Muito Fraco: Latossolos Vermelhos (LV) e Latossolos Vermelhos-Amarelos (LVA)

- Fraco: Latossolos Amarelos (LA)

- Forte/ Muito Forte: Cambissolos Háplicos (CX)

- Muito Forte: Argissolos Vermelhos (PV); Argissolos Vermelhos-Amarelos (PVA)

Figura 2 - Reclassificação da pedologia em graus de erodibilidade do solo

Figure 2 - Reclassification of pedology in degrees of soil erodibility

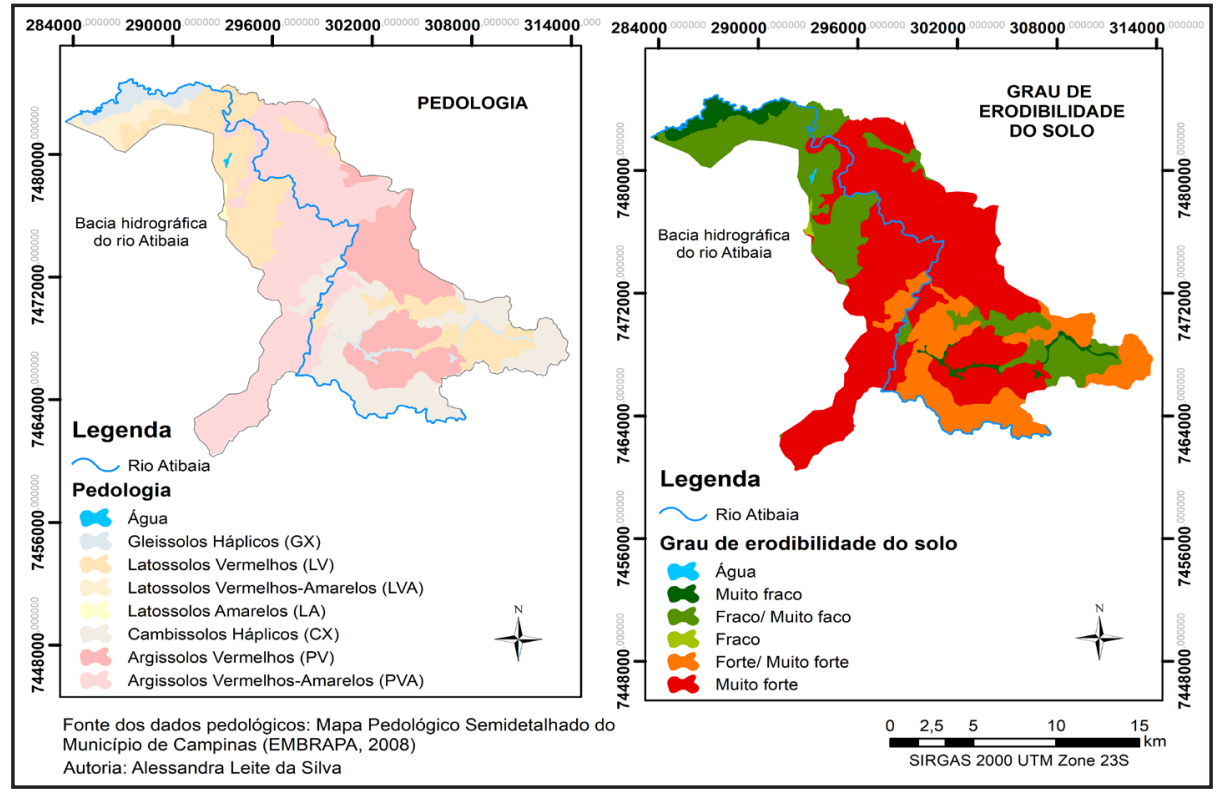

Fonte: Autores (2020) 


\section{Índice de Qualidade Ambiental $\left(I Q_{\text {rem }}\right)$}

A determinação da qualidade ambiental dos remanescentes florestais foi realizada a partir de análise multicriterial. Esse método se baseia no princípio de ponderação de valores, no qual existe possibilidade de comparar os pontos avaliados em referência a um ponto considerado como ideal. Como destaca Freitas (2012), nos ambientes antropizados o ponto de qualidade ideal é praticamente inatingível; apesar disso, a metodologia é indicada para identificar os fragmentos com necessidades mais urgentes, guiando a adequadas soluções de manejo e gestão. Essa análise foi realizada por meio da ponderação das métricas avaliadas, conforme apresentado na Tabela 1.

\section{Tabela 1 - Critérios de avaliação dos indicadores nos fragmentos florestais}

Table 1 - Criteria for evaluating indicators in forest fragments

\begin{tabular}{|c|c|c|c|c|c|}
\hline \multirow[b]{2}{*}{ Indicador } & \multicolumn{5}{|c|}{ Ponderação* } \\
\hline & 1 & 3 & 5 & 8 & 10 \\
\hline Tamanho do fragmento (ha) (AREA) & $<0,50$ & $0,50-1,00$ & $1,00-5,00$ & $5,00-20,00$ & $>20,00$ \\
\hline Índice de Área Central (CAI) & $<5 \%$ & $5-30 \%$ & $30-50 \%$ & $50-70 \%$ & $>70 \%$ \\
\hline Índice de Circularidade (IC) & - & - & $<0,65$ & $0,65-0,85$ & $>0,85$ \\
\hline Distância do vizinho mais próximo (ENN) & - & $>200$ & $120-200$ & $60-120$ & $<60$ \\
\hline Proximidade a curso d'água (PROXRIOS) & - & $>200 \mathrm{~m}$ & $120-200 \mathrm{~m}$ & $60-120 m$ & $<60 \mathrm{~m}$ \\
\hline Produção de água (AGUA) & - & - & Não & - & $\operatorname{Sim}$ \\
\hline $\begin{array}{l}\text { Grau de uso e ocupação do solo no } \\
\text { entorno (BORDA) }\end{array}$ & Classe 4 & Classe 3 & Classe 2 & Classe 1 & Classe 0 \\
\hline Grau de erodibilidade $(\text { EROD })^{* *}$ & Muito forte & Forte & Médio & Fraco & Muito fraco \\
\hline
\end{tabular}

Fonte: Autores (2020)

Em que: * As classes utilizadas para ponderação dos indicadores selecionados são baseadas na literatura: AREA (FREITAS, 2012); CAI (LIMA; FRANCISCO; BOHRER, 2017); IC (ETTO et al., 2013); ENN (ALMEIDA, 2008 apud MASSOLI; STATELLA; SANTOS, 2016); PROXRIOS (ALMEIDA, 2008 apud MASSOLI; STATELLA; SANTOS, 2016); AGUA (Autor); BORDA (CHAVES; SANTOS, 2009); EROD (SILVA; OLIVEIRA, 2015). ** As classificações intermediáriasde erodibilidade "Muito Forte/ Forte" e "Fraco/ Muito Fraco" receberam ponderação igual a 9 e 2, respectivamente.

Como nem todos os indicadores apresentam o mesmo peso para a consolidação do Índice de Qualidade Ambiental; dessa forma, foi aplicado o Método de Análise Hierárquica de Processos (AHP) para identificação dos coeficientes associados a cada indicador. Como o estudo aplicou um total de 8 variáveis, o valor de Índice de Consistência Aleatória (RI) foi de 1,41. A partir desse valor e do resultado do Índice de Consistência (CI) - Equação (2), calculou-se a Taxa de Consistência (CR) - Equação (3) - a fim de verificar que a mesma seja inferior a 10\%, indicando uma análise consistente.

$$
\begin{aligned}
& C I=\frac{\gamma_{\max }-n}{n-1} \\
& C R=\frac{C I}{R I}<10 \%
\end{aligned}
$$

A matriz de comparação construída com os oito indicadores selecionados, segundo o método AHP, teve dimensão $\mathrm{n}=8$. A partir dessa matriz foi calculado o vetor de Eigen associado 
a cada variável do Índice de Qualidade Ambiental $\left(\mathrm{IQ}_{\mathrm{rem}}\right)$. Dessa forma, o índice é estabelecido a partir de uma equação do tipo apresentado na Equação (4), onde a', b' e assim sucessivamente são os coeficientes da equação, determinados a partir da Análise Hierárquica de Processo (AHP).

$$
\begin{aligned}
I Q_{r e m} & =a^{\prime} \cdot A R E A+b^{\prime} \cdot C A I+c^{\prime} \cdot I C+ \\
& +d^{\prime} \cdot E N N+e^{\prime} \cdot P R O X R I O S+f^{\prime} \cdot A G U A+ \\
& +a^{\prime} \cdot B O R D A+h^{\prime} \cdot \text { EROD }
\end{aligned}
$$

Os valores de foram normalizados para valores entre 0 e 1 , de forma que a partir desse índice a qualidade ambiental dos remanescentes pôde ser classificada em: Muito Baixa (0,00 $0,20)$, Baixa $(0,20-0,40)$, Média $(0,40-0,60)$, Alta $(0,60-0,80)$ ou Muito Alta $(0,80-1,00)$.

\section{Resultados e discussões}

\section{Métricas de paisagem}

Pela análise dos dados obtidos a partir das métricas de paisagem observou-se que a maior parcela dos 1.368 remanescentes florestais apresenta tamanho muito pequeno (53,6\%), pequeno $(14,8 \%)$ e médio $(22,7 \%)$. Entretanto, apesar da predominância desses remanescentes menores (até 5,00 ha), sua contribuição em termos de área total é baixa, não chegando a $10 \%$, condição semelhante aos remanescentes de outras bacias hidrográficas, em estudos semelhantes (HIRSCH, 2003; CROUZEILLES et al., 2014; FERNANDES; FERNANDES, 2017).

Destaca-se que o LPI foi de $6,8 \%$, ou seja, o maior remanescente florestal identificado na sub-bacia do rio Atibaia é responsável por $6,8 \%$ de toda a área de vegetação florestal remanescente. Essa é uma informação importante, pois, como já citado, os fragmentos florestais de maiores áreas apresentam uma função ecológica e estrutural na paisagem muito significativa. Estes são denominados como fragmentos-matriz e atuam como área-fonte de recursos como dispersores, polinizadores, propágulos e genes para os remanescentes menores. Ou seja, contribuem para a manutenção da biodiversidade local na medida em que asseguram processos básicos como a dispersão e polinização (JESUS et al., 2015; SILVA et al. 2019).

Em contrapartida, os remanescentes menores e predominantes na bacia encontram-se mais susceptíveis aos efeitos de borda oriundos do contato com as pressões externas. Como evidenciado pelo CAI cujo valor é de $20,2 \%$, existe um baixo percentual de áreas centrais nos remanescentes florestais da sub-bacia do rio Atibaia. Muitos remanescentes tampouco apresentam área central, ou seja, constituem-se integralmente de área de borda; dessa forma, dos 1.368 remanescentes na sub-bacia do rio Atibaia, em Campinas, apenas 126(9,2\%) apresentam área central. Enquanto isso, o restante dos remanescentes desaparece completamente do mapa quando considerada essa área de borda, representando uma redução de área central de 79,8\% (Figura 3).

O baixo índice de área central afeta diretamente inúmeras espécies sensíveis que possuem requisitos ecológicos es pecíficos como: áreas preservadas e ausência do efeito de borda. (JESUS et al., 2015; MASSOLI; STATELLA; SANTOS, 2016). Um comparativo com os resultados de Hirsch (2003), onde o percentual de redução de área central foi de apenas $3 \%$, evidencia a significância de remanescentes florestais de tamanho grande para manutenção de habitats visto que, na área estudada pelo autor apesar de em pequeno número, existem remanescentes com mais de 1000 ha que representam quase $37 \%$ da área florestal. Mesmo assim, Hirsch (2003) apresenta que, para o caso de espécies de primatas, sobram poucos fragmentos de mata com condições ideais 
para fornecer habitat para sua sobrevivência. Em Campinas, a diminuição da cobertura vegetal tem provocado o aumento da fragmentação florestal e do efeito de borda, o que pode diminuir a qualidade ambiental das áreas remanescentes, provocando sérios prejuízos à fauna e flora, provocando, por exemplo, extinções locais e comprometendo a organização de espécies sob a forma de metapopulações. (HIRSCH, 2003; CAMPINAS, 2015).

\section{Figura 3 - Área total versus Área central dos remanescentes florestais}

Figure 3 - Total area versus Central area of forest remnants

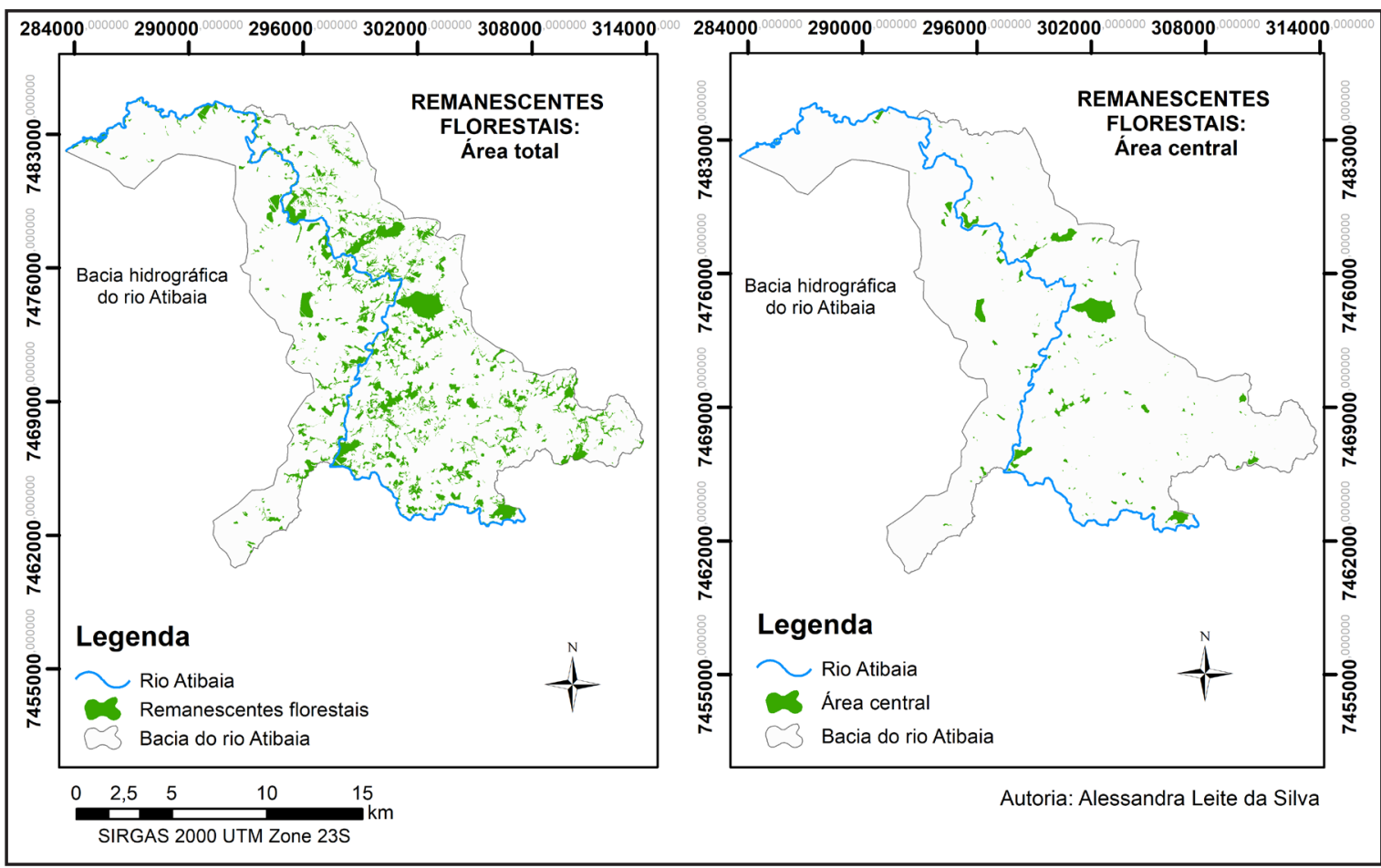

Fonte: Autores (2020)

Além do tamanho reduzido, o formato do remanescente também pode contribuir significativamente para a redução de sua área central. Isso porque, considerando o efeito de borda como distúrbio no ecossistema natural provocado pelos fatores que agem na área limítrofe entre o fragmento e seu entorno, remanescentes com formatos mais complexos e/ou mais alongados aumentam significativamente a área de contato entre o ecossistema florestal remanescente e a área modificada no seu entorno. Segundo o IC, 69,3\% dos remanescentes na sub-bacia do rio Atibaia apresentam formato alongado, $15,5 \%$ moderadamente alongado, e apenas $15,2 \%$ formato arredondado. $\mathrm{O}$ formato arredondado consiste no mais adequado para minimização do efeito de borda, já que há uma minimização da área de borda em relação à área total e área central encontra-se equidistante da borda (FREITAS, 2012). Como observado também por Hirsch (2003), os remanescentes que apresentam maiores dimensões e, logo, área central, possuem, por outro lado, um formato mais recortado e alongado.

Apesar da predominância de remanescentes alongados, a métrica ENN apontou que $80,8 \%$ dos remanescentes encontram-se a menos de $60 \mathrm{~m}$ do remanescente mais próximo. Além disso, são $11,7 \%$ dos fragmentos entre $60 \mathrm{~m}$ e $120 \mathrm{~m}$ do seu vizinho mais próximo e apenas $4,7 \%$ e $2,8 \%$ entre $120 \mathrm{~m}$ e $200 \mathrm{~m}$ e superior a $200 \mathrm{~m}$, respectivamente. Essa condição indica tanto a possibilidade de melhor fluxo gênico de fauna e de sementes, quanto pode estar associado a um alto grau de fragmentação nessa sub-bacia. Isso porque, a associação entre os fatores 'tamanho 
pequeno' e 'alta conectividade', como verificada também em outros estudos, pode indicar que recentemente um fragmento de maior área se fragmentou em fragmentos menores, porém próximos entre si, visto terem origem de um mesmo remanescente (HIRSCH, 2003; JESUS et al., 2015; MASSOLI; STATELLA, SANTOS, 2016; PATRA et al., 2018).

Essas condições criam um grande potencial para o estabelecimento de corredores ecológicos nessa área. De forma geral, os corredores ecológicos consistem em uma estratégia que visa reduzir os efeitos da fragmentação florestal, por meio de ações voltadas para a conexão de remanescentes florestais. Dessa forma, é construída na paisagem uma matriz permeável que garante o deslocamento e dispersão das espécies da fauna e da flora (HIRSCH, 2003; PEREIRA; CESTARO, 2016). Essa é, inclusive, uma das prioridades definidas no Código Florestal (Lei № 12.651/2012). Aliado a isso, é importante destacar que parte da área de estudo é abrangida por uma Unidade de Conservação de categoria Uso Sustentável, a APA Campinas. Essa UC, instituída pela lei municipal no 10.850/01, tem dentre outros objetivos a preservação dos remanescentes de mata nativa e recuperação de APPs, bem como a proteção dos mananciais hídricos, especialmente dos Rios Atibaia e Jaguari, os quais são utilizados para abastecimento público.

Entretanto, a conectividade dos remanescentes florestais não deve ser avaliada unicamente pelo fator de proximidade entre os remanescentes florestais; é importante que se considere também a malha de uso e ocupação no entorno desses fragmentos a fim de identificar se existe permeabilidade na paisagem que assegure não apenas a conectividade estrutural, mas também a funcional entre os remanescentes (FERNANDES; FERNANDES, 2017). Como destacam Pereira e Cestaro (2016), os estudos referentes aos corredores ecológicos requerem uma percepção multidisciplinar, que integre elementos físico-naturais, biológicos, socioeconômicos e legislação pertinente. Para tanto, devem partir de macroescalas e alcançar escalas de detalhes que permitam avaliar a possibilidade de efetiva conexão entre os remanescentes florestais.

No caso de Campinas/SP, o Plano do Verde e o Plano Diretor do município reconhecem a atual perda de biodiversidade de fauna e flora decorrentes da fragmentação dos habitats naturais e propõem algumas diretrizes para evitar, dentre outros problemas, que o desmatamento descontrolado e a expansão urbana sem planejamento promovam ainda mais perda para os ecossistemas naturais locais. Uma dessas propostas é justamente a promoção do reequilíbrio do ecossistema por meio da conservação e recuperação dos remanescentes florestais e criação de corredores ecológicos entre eles. Nesse contexto, as áreas marginais do rio Atibaia constituemse de áreas prioritárias indicadas para a implantação desses corredores ecológicos (CAMPINAS, 2015; CAMPINAS, 2017).

A proximidade de remanescentes a corpos d'águas é outro fator positivo. Tanto porque tal proximidade garante o fornecimento de recursos hídricos para a biota local e suas relações ecossistêmicas como também assegura a proteção dos recursos hídricos em termos de quantidade e qualidade. Como já ressaltado, as áreas florestais remanescentes e outras infraestruturas verdes garantem a proteção dos mananciais hídricos através da prevenção de erosão e de assoreamento em corpos d'água; redução da compactação do solo pelo efeito da chuva; aumento da infiltração de águas pluviais e consequente recarga das águas subterrâneas (MENEZES et al., 2016; PATRA et al., 2018).

Asub-bacia do rio Atibaia apresenta uma alta densidade hídrica, com uma frequência de cursos de águade $2,60 / \mathrm{km}^{2}$ segundo o Plano Diretor Estratégico do município (CAMPINAS, 2017). A métrica PROXRIOS apontou que $87,9 \%$ dos remanescentes florestais estão a menos de $60 \mathrm{~m}$ do curso d'água mais próximo. Para a faixa de $60 \mathrm{~m}$ a $120 \mathrm{~m}$ são 6,6\%; $120 \mathrm{~m}$ a $200 \mathrm{~m}$ apenas $3,7 \%$; e em distâncias superiores a $200 \mathrm{~m}$ somente 1,8\% dos remanescentes. Entretanto, apesar da alta densidade de cursos d'água e de nascentes na hidrografiado território de Campinas, muitas das nascentes do munícipio encontram-se desprotegidas de vegetação ripária (Figura 4).

É importante destacar que a proteção dos recursos hídricos através da presença de vegetação em seu entorno é um preceito já previsto no Código Florestal (Lei Federal N. 12.651/2012) sob o conceito de Área de Preservação Permanente (APP) que, dentre outras funções 
ambientais, facilitam o fluxo gênico e contribuem para a preservação dos recursos hídricos. Isso indica que os remanescentes próximos aos cursos d'água apresentam uma função ainda mais específica. Diante disso, o município de Campinas, através de seu Plano Diretor, já ressaltou a problemática da falta de matas ciliares e a necessidade de investimento na recuperação e conservação das APPs no entorno dos corpos hídricos (CAMPINAS, 2017).

Figura 4 - Proximidade dos remanescentes a cursos d'água (PROXRIOS) e produção de água (AGUA)

Figure 4 - Proximity of the remnants to water courses (PROXRIOS) and water production (AGUA)

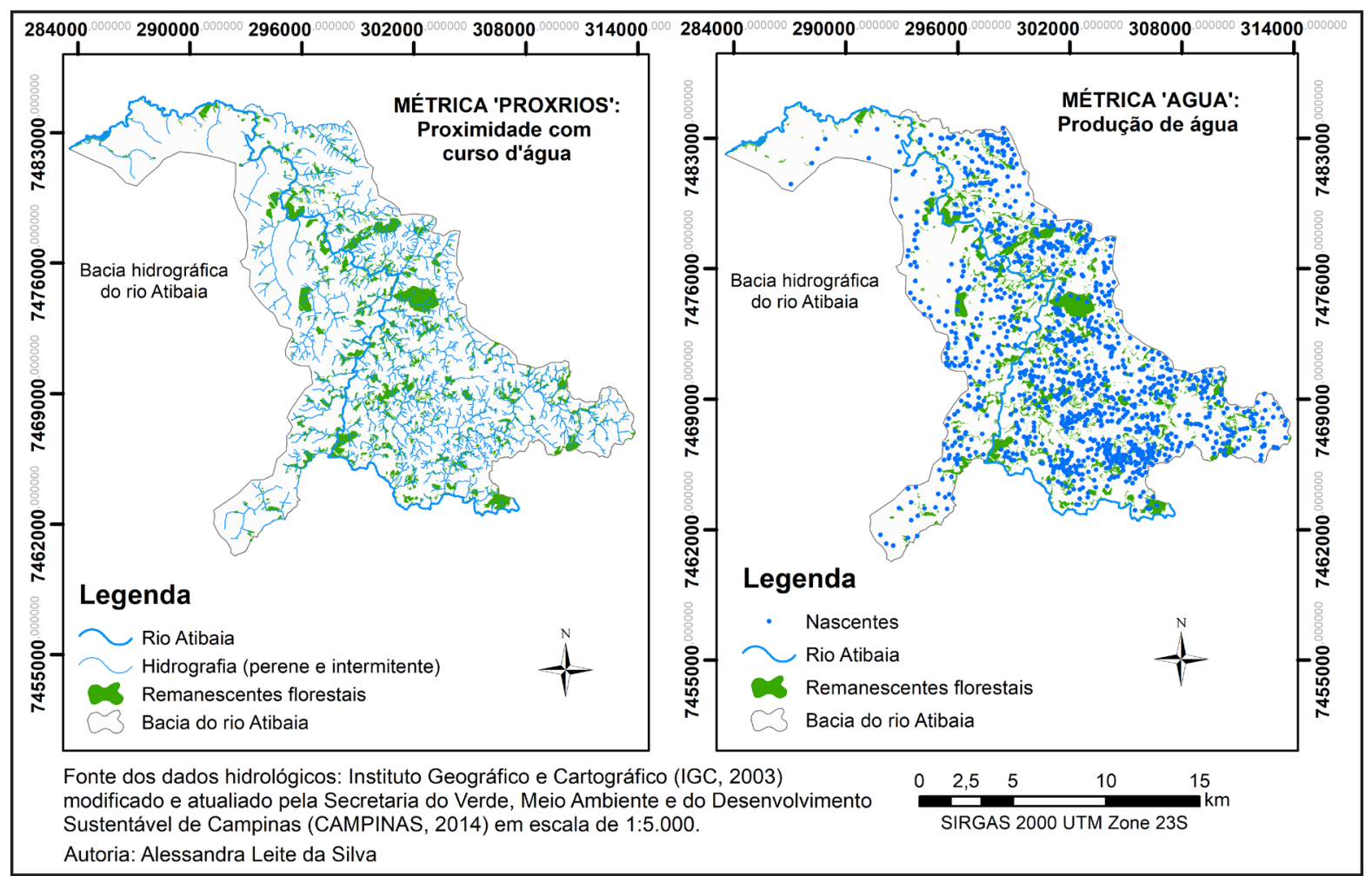

Fonte: Autores (2020)

Além disso, diante da alta e evidente potencialidade da sub-bacia do rio Atibaia para produção de água, essa sub-bacia torna-se ainda mais sensível ao processo de urbanização, adensamento e manejo inadequado do solo,visto que isso pode afetar a disponibilidade hídrica, provocando perdas na quantidade e na qualidade das águas (CAMPINAS, 2017). Um dos instrumentos legais já em vigor para amenizar esse problema foi a instituição da Área de Proteção Ambiental (APA Campinas) na área dos Distritos de Sousas e Joaquim Egídio, através da Lei Municipal N. ํ 10.850/2001, e cujos objetivos, dentre outros, é: (1) garantir a conservação do patrimônio natural, de forma a assegurar a qualidade de vida da população e a proteção dos ecossistemas regionais; (2) proteger os mananciais hídricos; e (3) controlar as pressões oriundas da urbanização e das atividades agrícolas e industriais, compatibilizando tais atividades com a conservação dos recursos naturais, visando o desenvolvimento sustentável (CAMPINAS, 2017).

Com relação ao uso e ocu pação do solo no entorno dos remanescentes, avaliado pela métrica BORDA, constatou-se que a maioria dos remanescentes florestais se encontram em contato com áreas classificadas como Classe 4 (61,7\%), ou seja, áreas caracterizadas pela presença de solo exposto, áreas degradadas, ruas e/ou edificações (CHAVES; SANTOS, 2009). Vale lembrar que no 
entorno dos remanescentes florestais podem ser verificadas áreas de classes distintas, contudo, para fins desta análise, foram consideradas as classes de maior pressão que fazem contato com os remanescentes em pelo menos em uma de suas faces. Dessa forma, em seguida aparece a Classe $2(30,6 \%)$, já que na bacia existe considerável ocupação do solo com atividades rurais, como pastagem e cultivo. As demais classes apresentaram valores significativamente menores: Classe $3(6,1 \%)$, Classe $1(1,5 \%)$ e Classe $0(0,1 \%)$ e estão relacionadas a atividades como culturas (perene, semiperene e temporária), campo natural e áreas de reflorestamento ou paisagens quase naturais, respectivamente.

De acordo com o Plano Diretor do município, as principais atividades econômicas rurais desenvolvidas nessa região envolvem as atividades agropecuárias, como produção de gado de leite e cultivo de café e cana. Além disso, é considerável a presença de grandes áreas reflorestadas com eucaliptos e de extensos campos limpos. Já com relação às glebas urbanas não parceladas, elas se constituem de áreas remanescentes de antigas fazendas situadas parcialmente na zona urbana, de forma adjacente às áreas loteadas ao longo da margem esquerda do rio Atibaia (CAMPINAS, 2017).

Quanto ao grau de erodibilidade do solo nos remanescentes florestais, contatou-se, por meio da métrica EROD, o seguinte percentual de remanescentes nas classes de erodibilidade: Muito Forte (64,4\%); Forte/ Muito Forte (21,1\%); Fraco/ Muito Fraco (8,8\%); e Muito Fraco (5,7\%). Ou seja, os remanescentes florestais estão predominantemente localizados em áreas com alto grau de erodibilidade do solo. Associado aos demais fatores já verificados, especialmente ao alto potencial hídrico, essa condição de solo corrobora para que a sub-bacia do rio Atibaia apresente alta vulnerabilidade ambiental. Como definem Liao, Li e Hou (2013), a vulnerabilidade ambiental consiste na instabilidade da estrutura inerente do ecossistema, de forma que uma alta vulnerabilidade indica que tal ecossistema apresenta baixa resistência e habilidades reduzidas de recuperação e regeneração após determinada interferência, resultando em mudanças irreversíveis no ecossistema.

A susceptibilidade de um solo à erosão está ainda associada a outros fatores, como: condições climáticas, características do relevo, práticas históricas de diferentes agentes sociais alterando as paisagens, e capacidade protetora da vegetação (COSTA; RODRIGUES, 2015; FUSHIMI; NUNES, 2018). Considerando esse último aspecto destaca-se ainda mais a relevância ambiental dos remanescentes florestais para a conservação do solo nessa bacia. Dessa forma, a implantação de práticas adequadas de conservação será eficaz tanto para o solo quanto para a água, reduzindo a velocidade do escoamento superficial, aumentando a infiltração e reduzindo os processos erosivos.

\section{Índice de Qualidade Ambiental $\left(I Q_{r e m}\right)$}

A matriz de comparação construída e o respectivo valor de Eigen correspondente a cada indicador estão apresentados na Tabela 2. A Taxa de Consistência (CR), calculada segundo equações preliminarmente apresentadas foi de $8,0 \%$, refletindo, portanto, uma análise consistente. Sendo assim, o Índice de Qualidade Ambiental ( $\left.\mathrm{IQ}_{\mathrm{rem}}\right)$ pôde ser representado pela Equação (5), apresentada a seguir.

$$
\begin{aligned}
I Q_{\text {rem }} & =0,079 \cdot A R E A+0,215 \cdot C A I+0,101 \cdot I C+ \\
& +0,108 \cdot E N N+0,053 \cdot \text { PROXRIOS }+0,224 \cdot A G U A+ \\
& +0,085 \cdot \text { BORDA }+0,136 \cdot \text { EROD }
\end{aligned}
$$




\section{Tabela 2 - Comparação pareada entre os indicadores selecionados - Metodologia AHP}

Table 2 - Paired comparison between selected indicators - AHP Methodology

\begin{tabular}{lccccccccc}
\hline & AREA & CAI & IC & ENN & $\begin{array}{c}\text { PROX } \\
\text { RIOS }\end{array}$ & AGUA & BORDA & EROD & $\begin{array}{c}\text { Vetor de } \\
\text { Eigen }\end{array}$ \\
\hline AREA & 1,000 & 0,250 & 1,000 & 0,500 & 2,000 & 0,333 & 1,000 & 1,000 & 0,079 \\
CAI & 4,000 & 1,000 & 3,000 & 2,000 & 4,000 & 0,500 & 3,000 & 2,000 & 0,215 \\
IC & 1,000 & 0,333 & 1,000 & 1,000 & 3,000 & 0,333 & 3,000 & 0,333 & 0,101 \\
ENN & 2,000 & 0,500 & 1,000 & 1,000 & 3,000 & 0,333 & 2,000 & 0,500 & 0,108 \\
PROXRIOS & 0,500 & 0,250 & 0,333 & 0,333 & 1,000 & 0,333 & 0,333 & 1,000 & 0,053 \\
AGUA & 3,000 & 2,000 & 3,000 & 3,000 & 3,000 & 1,000 & 2,000 & 1,000 & 0,224 \\
BORDA & 1,000 & 0,333 & 0,333 & 0,500 & 3,000 & 0,500 & 1,000 & 1,000 & 0,085 \\
EROD & 1,000 & 0,500 & 3,000 & 2,000 & 1,000 & 1,000 & 1,000 & 1,000 & 0,136 \\
\hline Soma & 13,500 & 5,166 & 12,666 & 10,333 & 20,000 & 4,333 & 13,333 & 7,833 & 1,000 \\
\hline
\end{tabular}

Fonte: Autores (2020)

Em que: $\mathrm{AREA}$ = Tamanho do Remanescente; CAI = Índice de Área Central; IC = Índice de Circularidade; ENN = Distância do Vizinho mais Próximo; PROXRIOS = Proximidade entre Remanescentes Florestais e Cursos d'Água; AGUA = Produção de Água; BORDA = Uso e Ocupação do Solo no Entorno; EROD = Grau de Erodibilidade do Solo.

Nesse Índice, as métricas com maior peso foram, respectivamente: AGUA, CAI, EROD, ENN, IC, BORDA, AREA e PROXRIOS. De acordo com o $I Q_{r e m}$ na sub-bacia do rio Atibaia, os remanescentes apresentam qualidade predominantemente média $(66,7 \%)$ e baixa $(29,8 \%)$. Apenas 3,4\% dos remanescentes apresentaram qualidade alta e somente um fragmento $(0,1 \%)$, que consiste em um fragmento de Floresta Estacional Semidecidual da Fazenda Santa Mariana Furnas, foi diagnosticado com qualidade ambiental muito alta (Figura 5).

Os resultados de, em geral medianos, refletem que apesar das pressões e vulnerabilidades aos quais estão sujeitos, a maioria dos remanescentes florestais não se encontram em condições tão degradadas que impossibilite ações de manejo e recuperação. Entretanto, é extremamente necessário que para uma gestão ambiental eficaz sejam assumidas novas diretrizes e ações para contenção da fragmentação florestal nessa área, pois como evidenciado de forma detalhada por cada métrica de paisagem, esses remanescentes têm alta vulnerabilidade ambiental, ao mesmo tempo em que exercem importantes funções ecossistêmicas.

Essas informações são, portanto, essenciais para os gestores locais que poderão propor ações de manejo adequadas, pautadas na atual condição da bacia hidrográfica e aproveitando seu potencial natural. Como destacam Andersson et al. (2014) no que diz respeito ao planejamento e gestão da infraestrutura verde urbana, os administradores locais exercem papel crucial, pois podem atuar redirecionando a urbanização para modelos integrados entre a humanidade e os sistemas de suporte à vida.

Lembrando que, com relação à recuperação de áreas degradadas, aquelas que se destacam como áreas prioritárias incluem justamente fragmentos que apresentam alto potencial de conectividade, além das áreas protegidas pela Legislação Ambiental, margens de rios, lagoas, lagos, nascentes e remanescentes de vegetação que compreendam tais coleções de água (CANET, 2007 apud RIAL; MORENO, 2015). Todas essas condições são verificadas na sub-bacia do rio Atibaia em Campinas, SP. 
Figura 5 - Qualidade ambiental dos remanescentes florestais na sub-bacia do rio Atibaia

Figure 5 - Environmental quality of forest remnants in the Atibaia River sub-basin

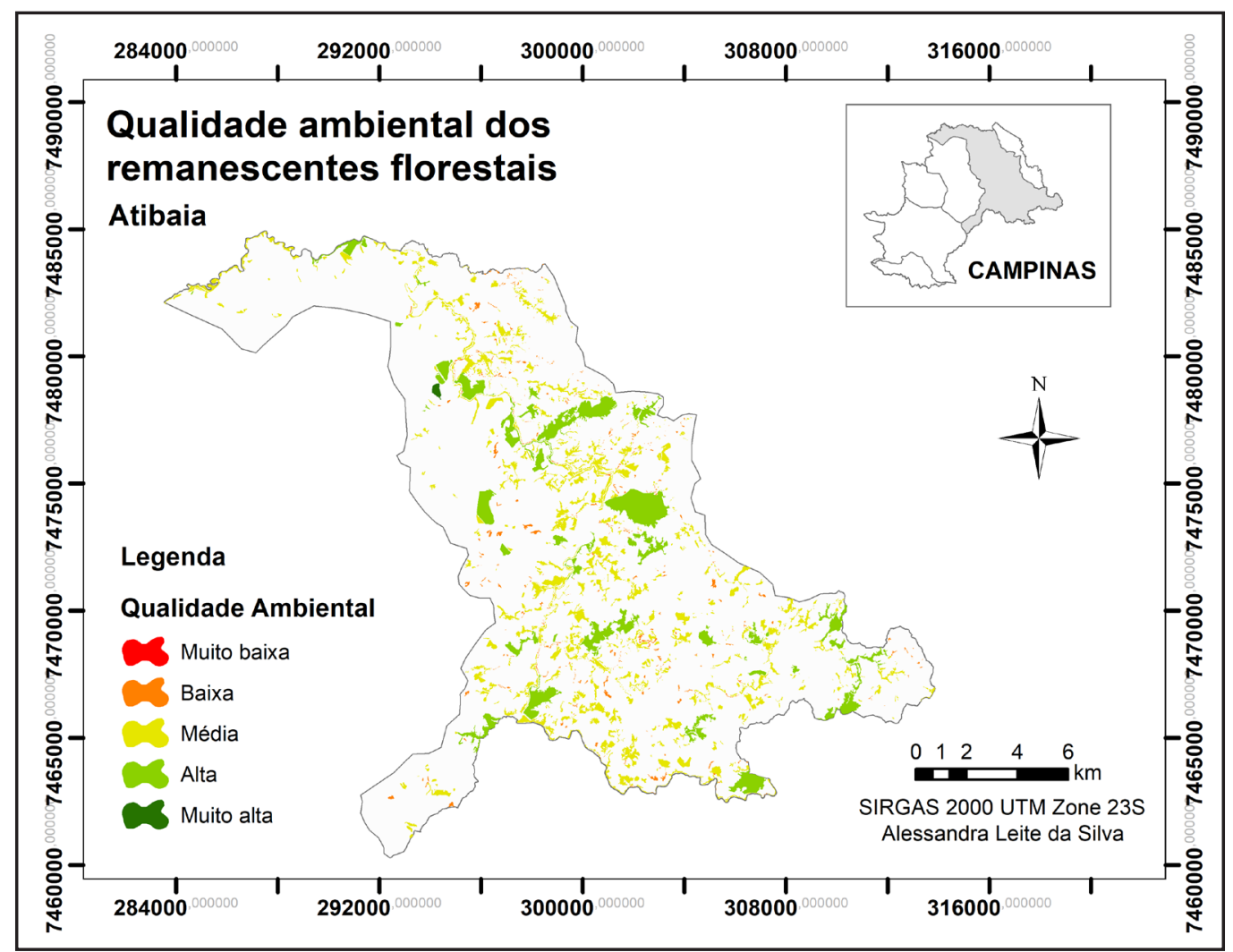

Fonte: Autores (2020)

\section{Conclusões}

A partir do presente estudo foi possível concluir que:

Os indicadores de métricas da paisagem selecionados descrevem principalmente a estrutura dos remanescentes florestais. Entretanto, constatou-se que os indicadores de forma podem ser instrumentos úteis para inferir informações acerca da composição dos remanescentes, tais como a presença ou ausência de espécies que necessitam de área nuclear para seu habitat.

Além disso, aliado aos indicadores de proximidade e uso e ocupação podem ser importantes indicativos das funções prioritárias dos remanescentes. Essa condição auxilia a determinação dos serviços ecossistêmicos potenciais nessas áreas, tais como o fornecimento de serviços da tipologia cultural nos remanescentes que não apresentam área suficiente para servir, por exemplo, para o fornecimento de habitat ou alimentos, mas estão mais próximos aos aglomerados urbanos e, portanto, mais acessíveis. Dessa forma, mais estudos têm sido realizados buscando correlacionar diretamente os indicadores citados neste estudo ao fornecimento de serviços ecossistêmicos.

A paisagem natural da sub-bacia do rio Atibaia encontra-se altamente fragmentada evidenciado pelo elevado número de remanescentes florestais, especialmente fragmentos pequenos, porém localizados próximos uns aos outros;

Uma das principais fragilidades identificadas nos remanescentes florestais da sub-bacia do Rio Atibaia é justamente o tamanho reduzido. Esse fator conduz à baixa representativa de 
áreas centrais (apenas 20,14\%) e evidencia o quanto os remanescentes encontram-se sujeitos ao efeito de borda;

A sub-bacia do Rio Atibaia é uma grande produtora de água para abastecimento tanto do município de Campinas, quanto de municípios vizinhos; isso ressalta ainda mais a necessidade da promoção de estratégias de conservação de tais remanescentes, especialmente visando promover o aumento de sua área efetiva e garantir sua potencialidade na produção de água e conservação da qualidade dos mananciais hídricos do município.

\section{Agradecimentos}

À Fundação de Amparo à Pesquisa do Estado de São Paulo (FAPESP), pela Bolsa de Mestrado concedida ao primeiro autor (Processo no 2017/26603-4), à Coordenação de Aperfeiçoamento de Pessoal de Nível Superior (CAPES) e à Pontifícia Universidade Católica de Campinas (PUC-Campinas).

\section{Referências}

AGÊNCIA DE ÁGUA PCJ. Caracterização das bacias PCJ. Disponível em: http://www. agenciapcj.org.br/antigo/download/RS-04-06_Capitulo-2.pdf. Acesso em 22 set. 2019.

ANDERSSON, E. et al. Reconnecting Cities to the Biosphere: Stewardship of Green Infrastructure and Urban Ecosystem Services. AMBIO, Stockholm, v. 43, n. 4, p. 445-453, 2014. https://doi. org/10.1007/s13280-014-0506-y

CAMPINAS. Prefeitura Municipal de Campinas. Plano Diretor Estratégico. Campinas: (SEPLAMA) Secretaria de Planejamento e Desenvolvimento Urbano, 2017.

CAMPINAS. Prefeitura Municipal de Campinas. Plano Municipal do Verde. Campinas: (SVDS) Secretaria do Verde, Meio Ambiente e Desenvolvimento Sustentável, 2015.

CASTRO-COMA, M.; MARTÍ-COSTA, M. Comunes urbanos: de la gestión colectiva al derecho a la ciudad. EURE, Santiago, v. 42, n. 125, p. 131-153, jan. 2016. http://dx.doi.org/10.4067/S025071612016000100006

CHAVES, H. M. L.; SANTOS, L.B. Ocupação do solo, fragmentação da paisagem e qualidade da água em uma pequena bacia hidrográfica. Revista Brasileira de Engenharia Agrícola e Ambiental, Campina Grande, v. 13, p. 922-930, dez. 2009. https://doi.org/10.1590/S141543662009000700015

COSTA, Y. T.; RODRIGUES, S. C. Relação entre cobertura vegetal e erosão em parcelas representativas de Cerrado. Rev. Geográfica Acadêmica, Boa Vista, v. 9, n. 2, p. 61-75, 2015. https://doi.org/10.18227/1678-7226rga.v9i2.3160

CROUZEILLES, R.; PREVEDELLO, J. A.; FIGUEIREDO, M. S. L.; LORINI, M. L.; GRELLE, C. E. V. The effects of the number, size and isolation of patches along a gradient of native vegetation cover: how can we increment habitat availability? Landscape Ecology, Tempe, v. 29, p. 479-489, 2014. https://doi.org/10.1007/s10980-013-9978-6

DEMANBORO, A. C.; LAURENTIS, G. L.; BETTINE, S. C. Cenários ambientais na bacia do rio Atibaia. Revista Engenharia Sanitária e Ambiental, Rio Claro, v. 18, n. 1, p. 27-37, jan./mar. 2013. https://doi.org/10.1590/S1413-41522013000100004

ETTO, T. L.; LONGO, R. M.; ARRUDA, D. R.; INVENIONI, R. Ecologia da paisagem de remanescentes florestais na bacia hidrográfica do Ribeirão das Pedras - Campinas -SP. Revista 
Árvore, Viçosa,v.37, n.6, p.1063-1071, dez.2013. https://doi.org/10.1590/S0100-67622013000600008

FERNANDES, M.; FERNANDES, R. D. M. Análise Espacial da Fragmentação Florestal da Bacia do Rio Ubá - RJ. Ciência Florestal, Santa Maria, v. 27, n. 4, p. 1429-1439, 2017. http://dx.doi. org/10.5902/1980509830330

FREITAS, E. P. Análise integrada do mapa de uso e ocupação das terras da microbacia do Rio Jundiaí-Mirim para fins de gestão ambiental. 2012. 132 f. Dissertação (Mestrado em Agricultura Tropical e Subtropical), Instituto Agronômico de Campinas, Campinas - SP, 2012.

FUSHIMI, M.; NUNES, J. O. R. Vulnerabilidade ambiental aos processos erosivos lineares das paisagens de parte dos municípios de Marabá Paulista (SP) e Presidente Epitácio (SP), Brasil. Revista da Associação Nacional de Pós-graduação e Pesquisa em Geografia (Anpege), João Pessoa, v. 14, n. 23, p. 5-27, jan./abr. 2018. http://dx.doi.org/10.5418/RA2018.1423.0001

HERSPERGER, A. M.; OlIVEIRA, E.; PAGLIARIN, S.; PALKA, G.; VERBURG, P.; BOLLIGER, J.; GRADINARU, S. Urban land-use change: The role of strategic spatial planning. Global Environmental Change, Melbourne v. 51, p. 32-42, 2018. https://doi.org/10.1016/j. gloenvcha.2018.05.001

HIRSCH, A. Habitat fragmentation and priority areas for primate conservation in the Rio Doce Basin, Minas Gerais. Neotropical Primates, Belo Horizonte, v. 11, n. 3, p. 195-196, 2003.

JESUS, E. N.; FERREIRA, R. A.; ARAGÃO, A. G.; SANTOS, T. I. S.; ROCHA, S. L. Estrutura dos fragmentos florestais da Bacia Hidrográfica do Rio Poxim-SE, como subsídio à restauração ecológica. Revista Árvore, Viçosa, v. 39, n. 3, p. 467-474, 2015. http://dx.doi.org/10.1590/010067622015000300007

LAWLEY, V.; LEWIS, M.; CLARKE, K.; OSTENDORF, B. Site-based and remote sensing methods for monitoring indicators of vegetation condition: An Australian review. Ecological Indicators, Coimbra, v. 60, p. 1273-1283, 2016. https://doi.org/10.1016/j.ecolind.2015.03.021

LIAO, X.; LI, W.; HOU, J. Application of GIS based ecological vulnerability evaluation in environmental impact assessment of master plan of coal mining area. Procedia Environmental Sciences, Netherlands, v. 18, p. 271-276, 2013. https://doi.org/10.1016/j.proenv.2013.04.035

LIMA, B. C.; FRANCISCO, C. N.; BOHRER, C. B. DE A. Deslizamentos e fragmentação florestal na região serrana do Estado do Rio de Janeiro. Ciência Florestal, Santa Maria, v. 27, n. 4, p. 1283-1295, 2017. http://dx.doi.org/10.5902/1980509830321

LONGO, R. M.; SILVA, A. L.; BETTINE, S. C.; DEMANBORO, A. C.; BRESSANE, A. FENGLER, F. H.; RIBEIRO, A. Í. Environmental quality in urban forests in Campinas - São Paulo state/ Brazil. International Journal of Environmental Impact, Southampton, v. 2, p. 117-130, 2019. http://dx.doi.org/10.2495/EI-V2-N2-117-130

MASSOLI, J. V.; STATELLA, T.; SANTOS, V. S. Estimativa da fragmentação florestal na microbacia Sepotubinha, Nova Marilândia - MT, entre os anos de 1990 a 2014. Caminhos de Geografia, Uberlândia, v. 17, n. 60, p. 48-60, 2016. http://dx.doi.org/10.14393/RCG176004

MENEZES, J. P.; BITTENCOURT, R. P.; FARIAS, M. S.; BELLO, I. P.; FIA, R.; OLIVEIRA, L. F. C. Relação entre padrões e uso e ocupação do solo e qualidade da água em uma bacia hidrográfica urbana. Revista Engenharia Sanitária e Ambiental, Rio Claro, v. 21, n. 3, p. 519-534, jul./set. 2016. http://dx.doi.org/10.1590/S1413-41522016145405

PATRA, S.; SAHOO, S.; MISHRA, P.; MAHAPATRA, S. C. Impacts of urbanization on land use /cover changes and its probable implications on local climate and groundwater level. Journal of Urban Management, Hangzhou, v. 7, p. 70-84, 2018. https://doi.org/10.1016/j.jum.2018.04.006

PEREIRA, V. H. C.; CESTARO, L. A. Corredores Ecológicos no Brasil: Avaliação sobre os principais critérios utilizados para definição de áreas potenciais. Caminhos de Geografia, 
Uberlândia, v. 17, n. 58, p. 16-33, jun. 2016. https://doi.org/10.14393/RCG175802

RIAL, A. B.; MORENO, E. C. Corredores Ecológicos como Estratégia para la Conservación de los Ecossistemas Boscosos de la Reserva Florestal de Caparo, Venezuela. Interciencia, Caracas, v. 40, n. 4 , p. $275-281,2015$.

SÃo PAUlo. DATAGEO - Sistema Ambiental Paulista. Uso e Cobertura da Terra da UGRHI 05 (PCJ). 2013. Disponível em: <http://datageo.ambiente.sp.gov.br/>. Acesso em 15 jul. 2018.

SILVA, A. L.; LONGO, R. M.; BRESSANE, A.; CARVALHO, M. F. H. Classificação de fragmentos florestais urbanos com base em métricas da paisagem. Revista Ciência Florestal, Santa Maria, v. 29, n. 3, p.1254-1269. 2019. https://doi.org/10.5902/1980509830201

SILVA, G. G.; OLIVEIRA, L. N. Análise da suscetibilidade e potencial à erosão laminar no município de São Miguel do Araguaia - GO. In: SIMPÓSIO BRASILEIRO DE SENSORIAMENTO REMOTO - SBSR, 17., 2015, João Pessoa. Anais... João Pessoa: INPE, 2015. p. 6511-6518. Disponível em: http://www.dsr.inpe.br/sbsr2015/files/p1412.pdf. Acesso em 15 nov. 2019.

SIQUEIRA, M. N., CASTRO, S. S., FARIA, K. M. S. Geografia e Ecologia da Paisagem: pontos para discussão. Sociedade e Natureza, Uberlândia, v. 25, n. 3, p.557-566, set./dez. 2013. https:// doi.org/10.1590/S1982-45132013000300009

WU, Y.; ZHU, X.; GAO, W.; QIAN, F. The spatial characteristics of coupling relationship between urbanization and eco-environment in the Pan Yangtze River Delta. Energy Procedia, [S.I], v. 152, p. 1121-1126, 2018. https://doi.org/10.1016/j.egypro.2018.09.136 